\title{
Experimental Study on Flexural Behaviour of Concrete Filled Steel Box Members
}

\author{
Aslam Amirahmad \\ Department of Civil Engineering, College of Engineering, Salman Bin Abdulaziz University, Al-Kharj, KSA \\ Email: a.ahmad@sau.edu.sa, draslam15@rediffmail.com
}

Received 1 January 2014; revised 1 February 2014; accepted 8 February 2014

Copyright (C) 2014 by author and Scientific Research Publishing Inc.

This work is licensed under the Creative Commons Attribution International License (CC BY).

http://creativecommons.org/licenses/by/4.0/

(c) (i) Open Access

\begin{abstract}
Recently, the use of composite structures composed of steel plate and in filled concrete has become increasingly popular in Civil engineering structures. This is because of their excellent earthquake resistant properties such as energy absorption capacity. In the present investigation, an experimental study has been carried out. The main objective of this study is to find out the ultimate moment carrying capacity of concrete filled steel box members (CFSB).
\end{abstract}

\section{Keywords}

CFSB

\section{Introduction}

Concrete filled steel box members have recently experienced renaisscence in their use throughout the world. In concrete filled columns, there is a mutual enhancement of ductility, because steel plate provides confinement for the concrete, which in turn prevents the inward buckling of the plate.

In recent years, Brain Uy [1] dealt with strength behaviour of concrete filled steel box short columns under combined action of axial compression and bending. To ascertain the behaviour, a four-point loading beam test was carried out. Weizi and Shahrooz [2] focused on concrete filled tubular columns. The main objective of this study is to evaluate the applicability of ACI Building Code. Brain [3] investigated the local and post local buckling behaviour of welded sections such as box or wide flange I-Sections. He did experimental study on both hollow and concrete-filled steel box sections.

Based on the existing literature, it is concluded that the limited information is available regarding the behaviour of concrete filled steel box members under flexural. There is no experimental study for comparing the strength of concrete filled steel box members with conventional reinforced concrete members. 


\section{Scope and Objective}

The present study is concerned with an experimental investigation on the flexural behaviour of concrete filled steel box members. The purpose of this study is to examine the ultimate moment carrying capacity of concrete filled steel box members using concrete of various grade viz M20, M30 \& M40. This work presents a simple comparative study between the concrete filled steel box members and conventional reinforced cement concrete members.

\section{Fabrication of Specimen}

Steel box sections were fabricated using steel plate of $3 \mathrm{~mm}$ thickness and were typically composed of mild structural steel with a nominal tensile yield stress of $300 \mathrm{MPa}$. The complete steel box sections (Shown in Figure 1) having same thickness was cut from a single batch of rolling using gas cutting process. The folder component plates were initially tack welded, while the internal bracing was provided to minimize geometric imperfections. Extra case had been taken while welding the specimens to present wrapping. All the sections were then longitudinally fillet weld in a configuration illustrated after the welding procedure. The dimensions of all the sections were kept as $100 \mathrm{~mm} \times 100 \mathrm{~mm}$. The lengths of the sections were kept as $750 \mathrm{~mm}$ Figure 2 shown the specimens.

\subsection{Casting of Specimens}

Concrete mix was poured into the cold form fabricated steel sections held in a slightly tilted position, to avoid air packets. Tamping of steel sections using wooden rammers helped to achieve uniform and void free concrete.



Figure 1. Steel box section.

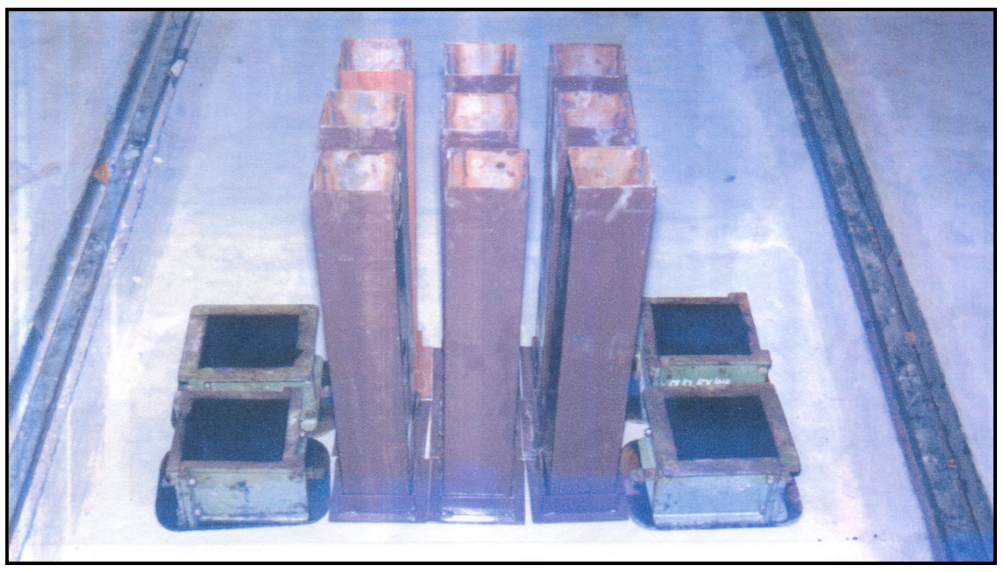

Figure 2. Steel box sections $(100 \mathrm{~mm} \times 100 \mathrm{~mm} \times 750 \mathrm{~mm})$ and standard mild steel mould. 
Control concrete cubes were also cast in standard steel mould for each batch of mixing. After $24 \pm 1 / 2$ hours, the test specimens and cubes were cured in a curing tank for 28 days. The casting procedure is shown in Figure 3.

\subsection{Experimental Procedure}

The cubes were tested in hydraulic compression testing machine (as shown in Figure 4). For the purpose of investigating the flexural behaviour of concrete steel box members, a two-point loading beam test was carried out for each specimen.

The specimen was placed in UTM (Figure 5) in such a manner that the load was applied to upper most surface of the specimen along two lines spaced @ $20 \mathrm{~cm}$ apart. The load was applied without shock and increased continuously the corresponding deflection was taken until the specimen reaches the ultimate load.

\section{Results and Discussions}

The load deflection graphs for M20, M30 and M40 specimens tested are shown in Figures 6-14. The graphs illustrate that all the beam members had a significant yielding pattern, thus illustrating the ductility of these members under static flexural loading. This is quite important that these members had no reinforcement. The

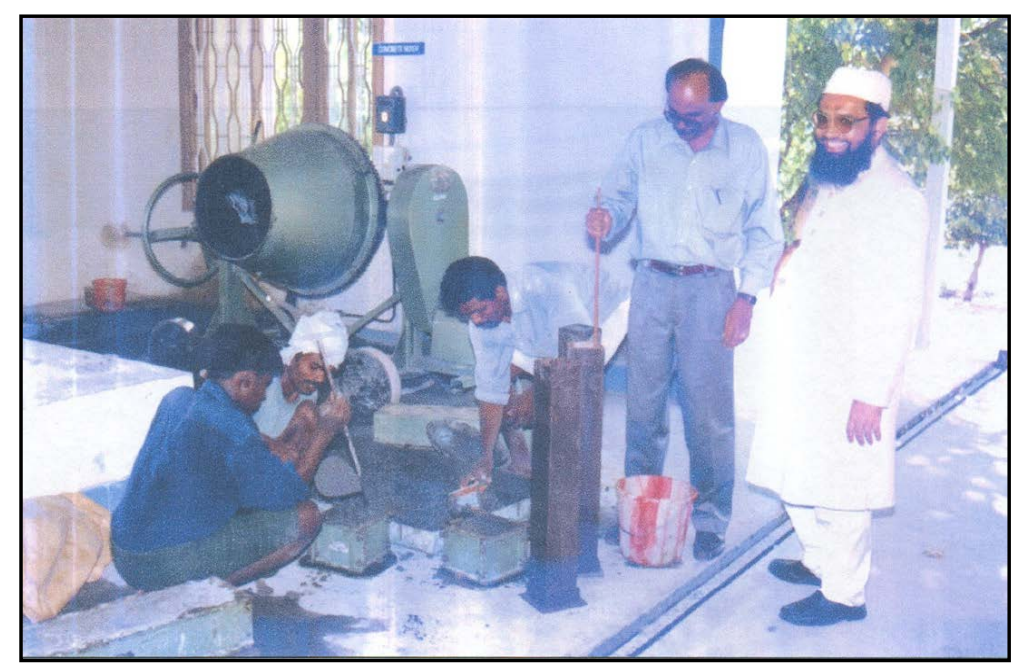

Figure 3. Casting of specimens.

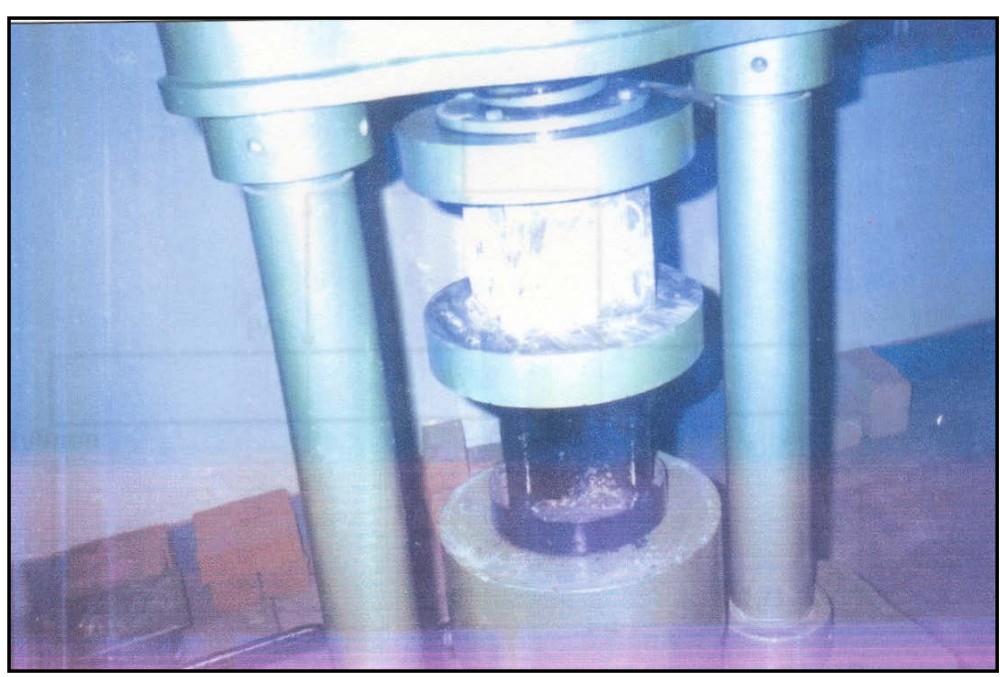

Figure 4. Standard cubes of concrete was tested in hydraulic compression testing machine. 


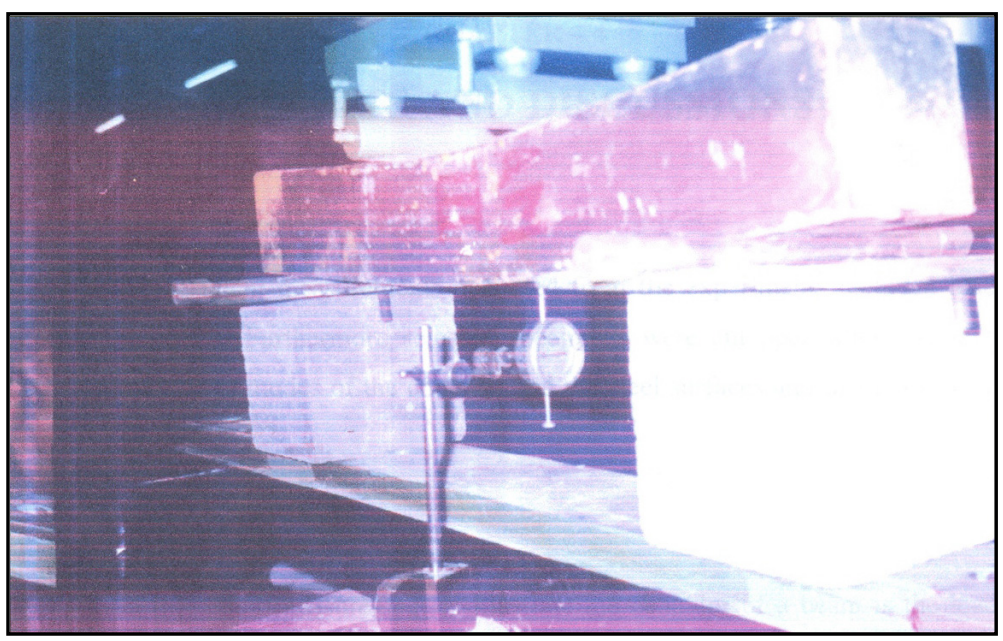

Figure 5. Two-point loading beam test by UTM.

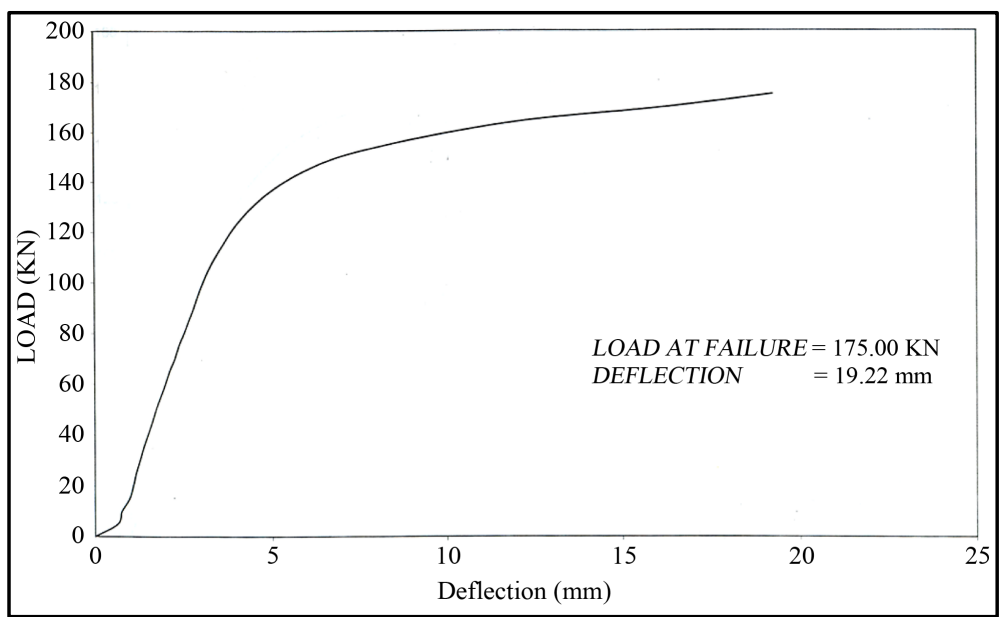

Figure 6. Load vs. deflection response M20-I specimen.

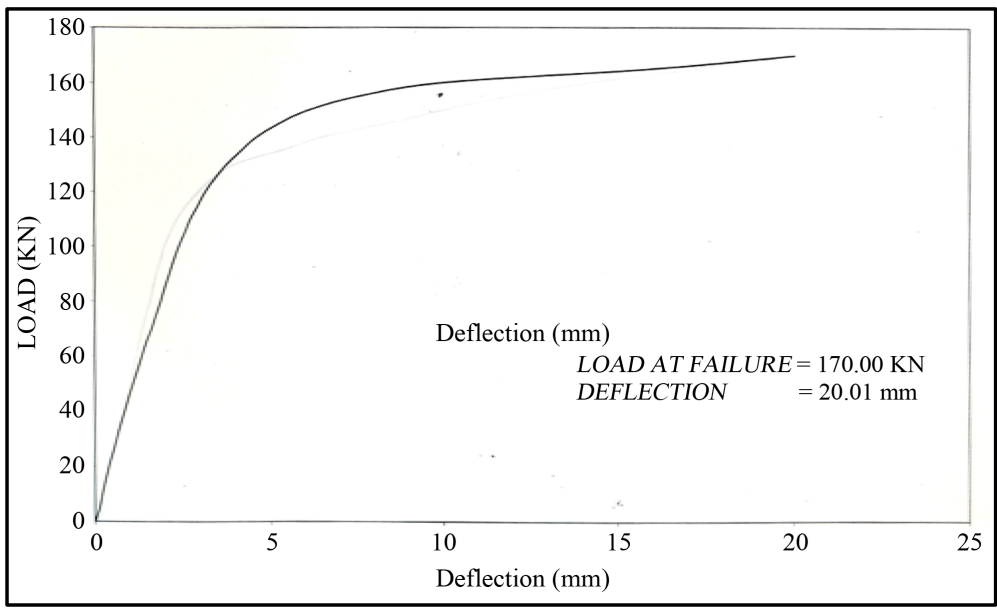

Figure 7. Load vs. deflection response M20-II specimen.

external steel cashing of the concrete to provide ductile behaviour that is superior to reinforced concrete members. 


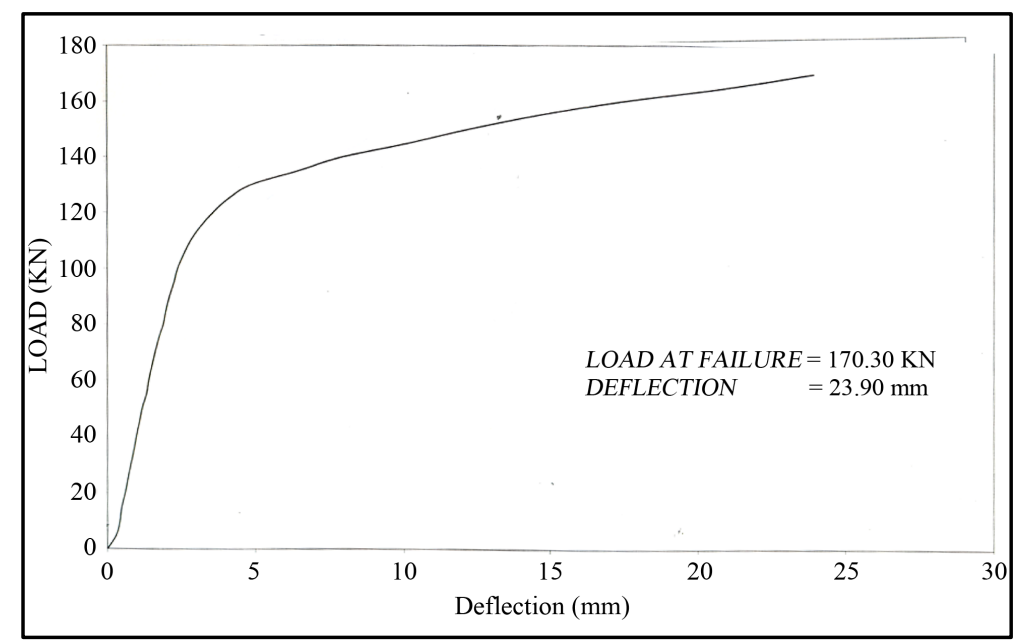

Figure 8. Load vs. deflection response M20-III specimen.

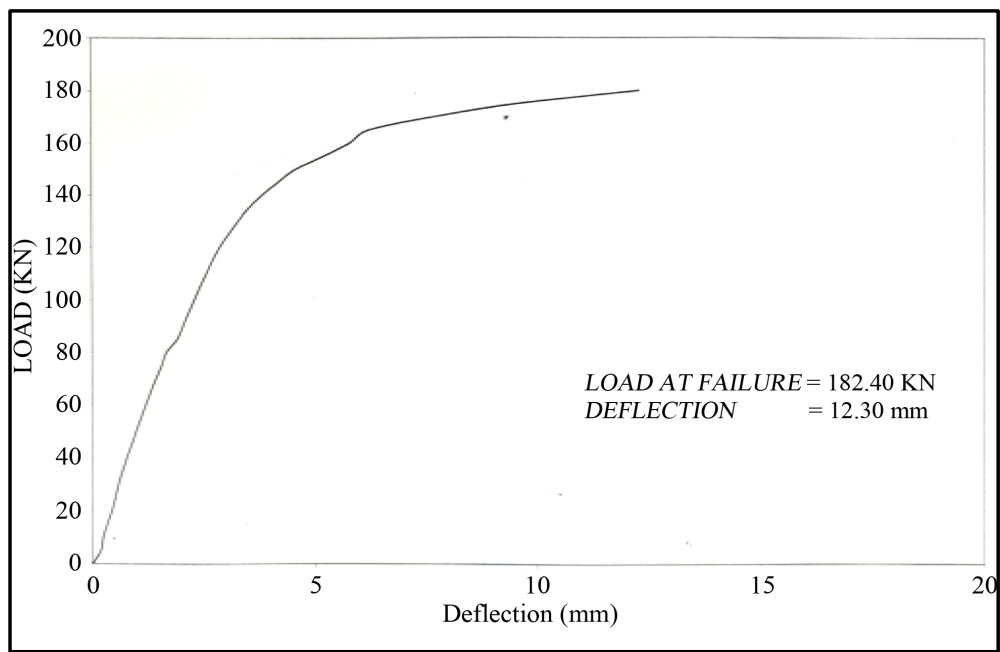

Figure 9. Load vs. deflection response M30-I specimen.

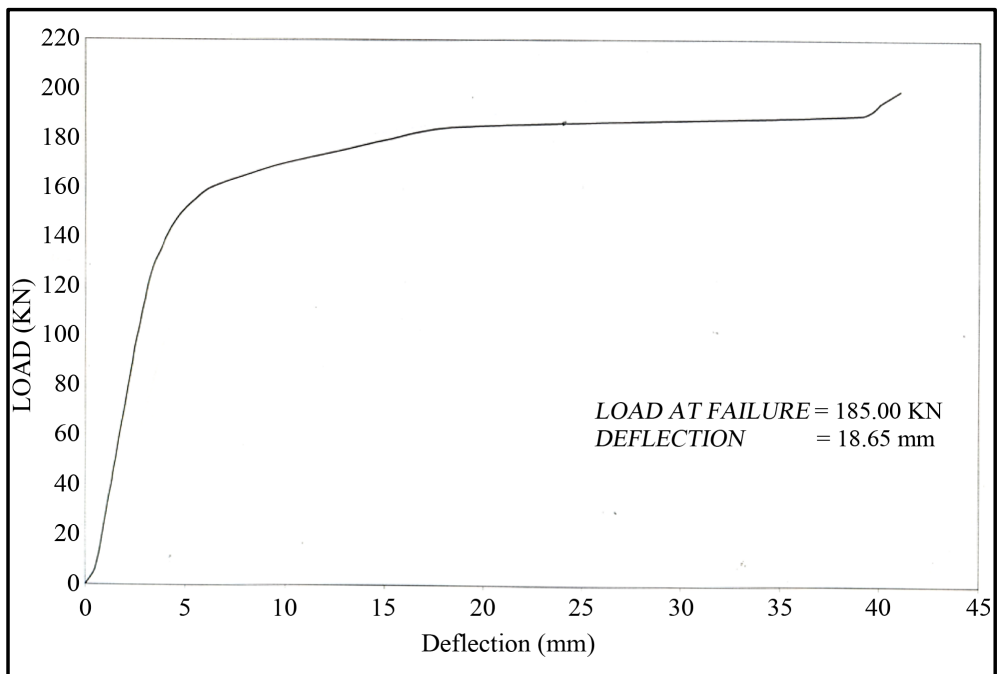

Figure 10. Load vs. deflection response M30-II specimen. 




Figure 11. Load vs. deflection response M30-II specimen.

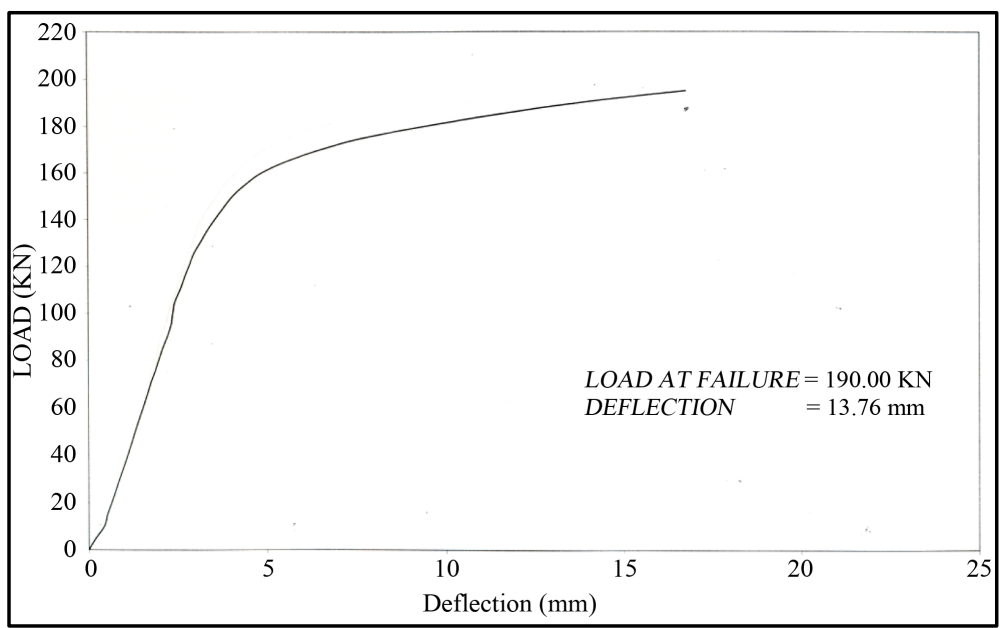

Figure 12. Load vs. deflection response M30-II specimen.



Figure 13. Load vs. deflection response M30-II specimen.

The failure mode of the specimen beams is shown in Figures 15-18. All beam specimens were designed to behave in a purely flexural manner. Primary tension failure occurred in all beams and a plastic hinge is formed with local buckling of upper most compression flange. 


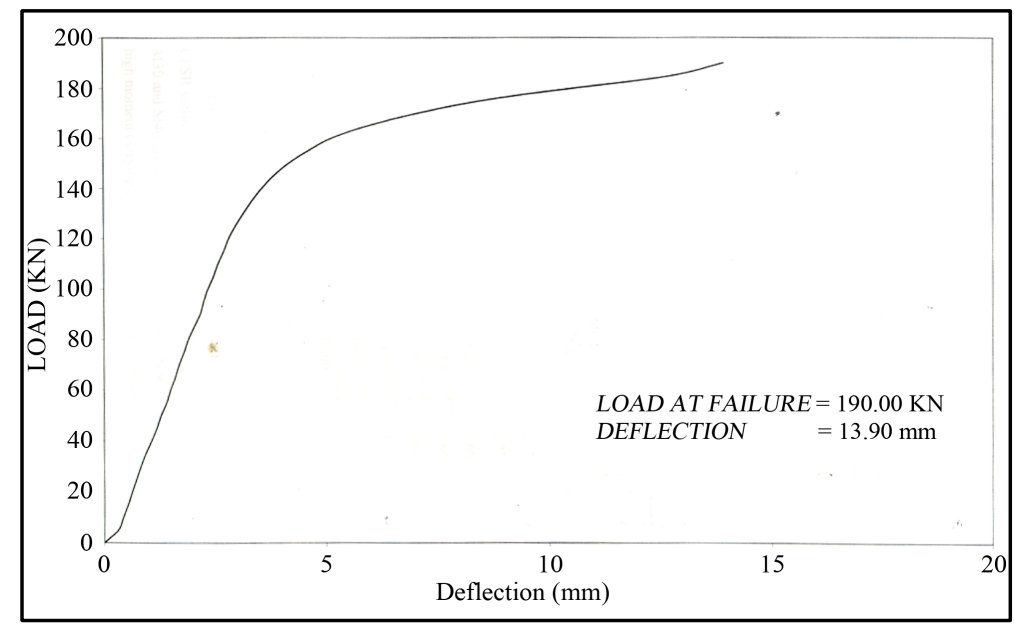

Figure 14. Load vs. deflection response M40-II specimen.

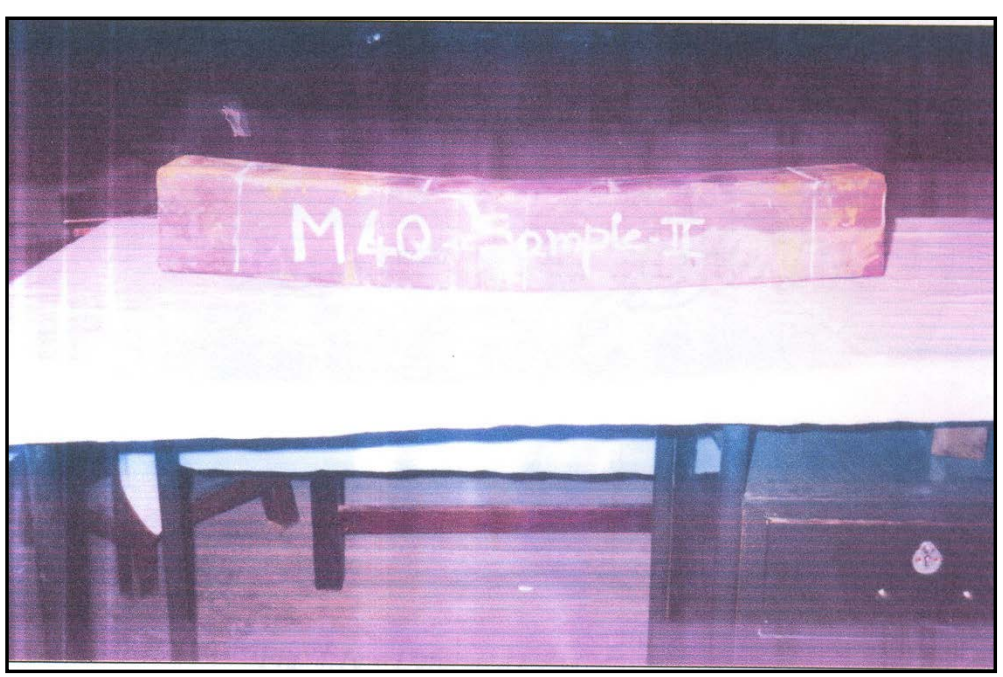

Figure 15. Failure mode of beam specimen.

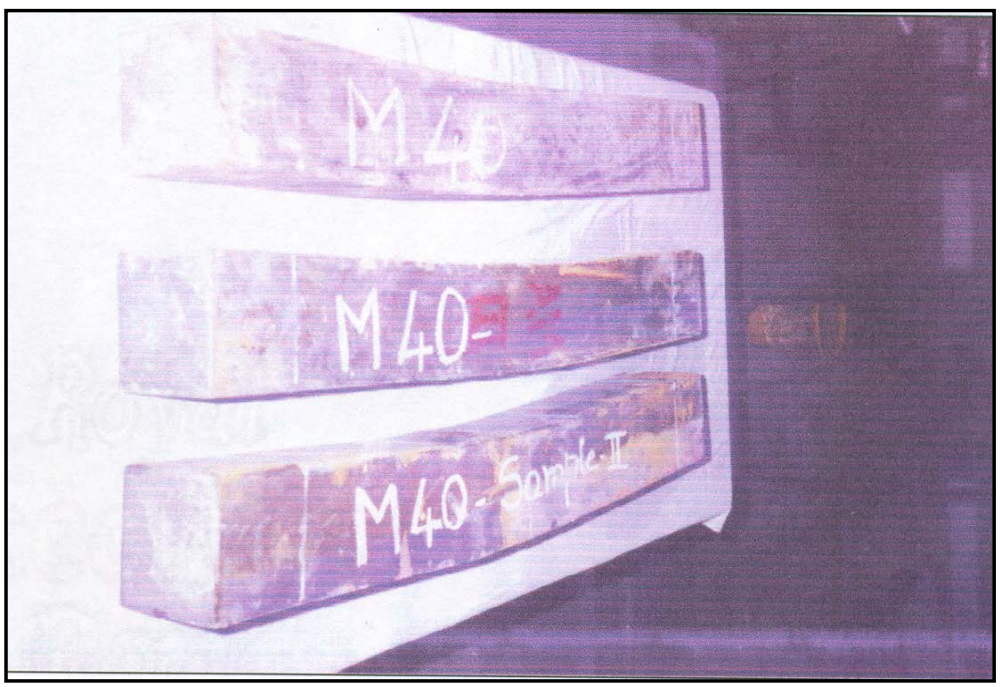

Figure 16. Primary tension failure occurred in all beams. 


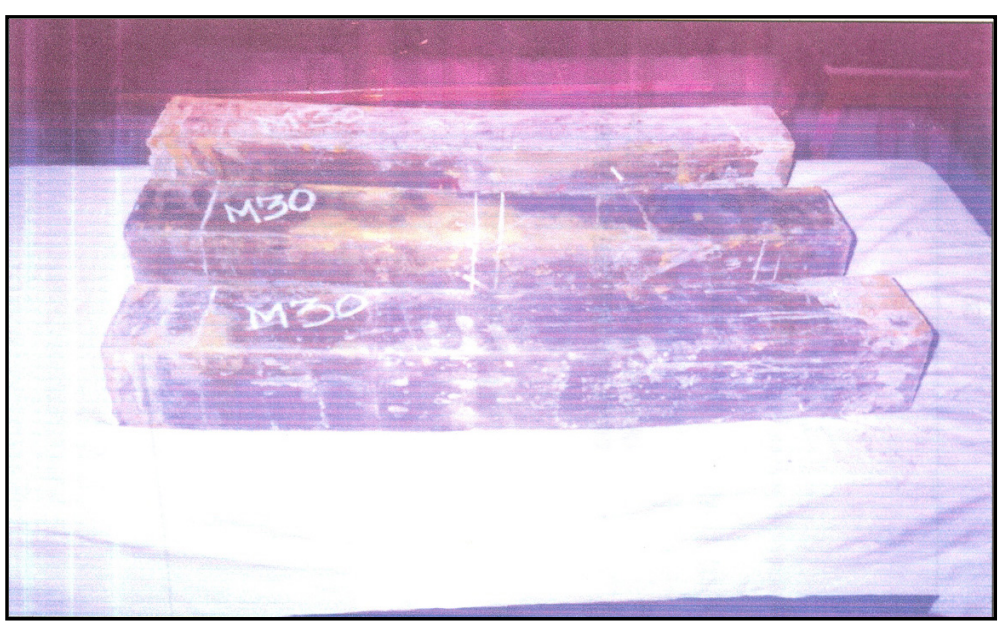

Figure 17. A plastic hinge is formed with local buckling of upper most compression flange.



Figure 18. Failure mode of beam specimen.

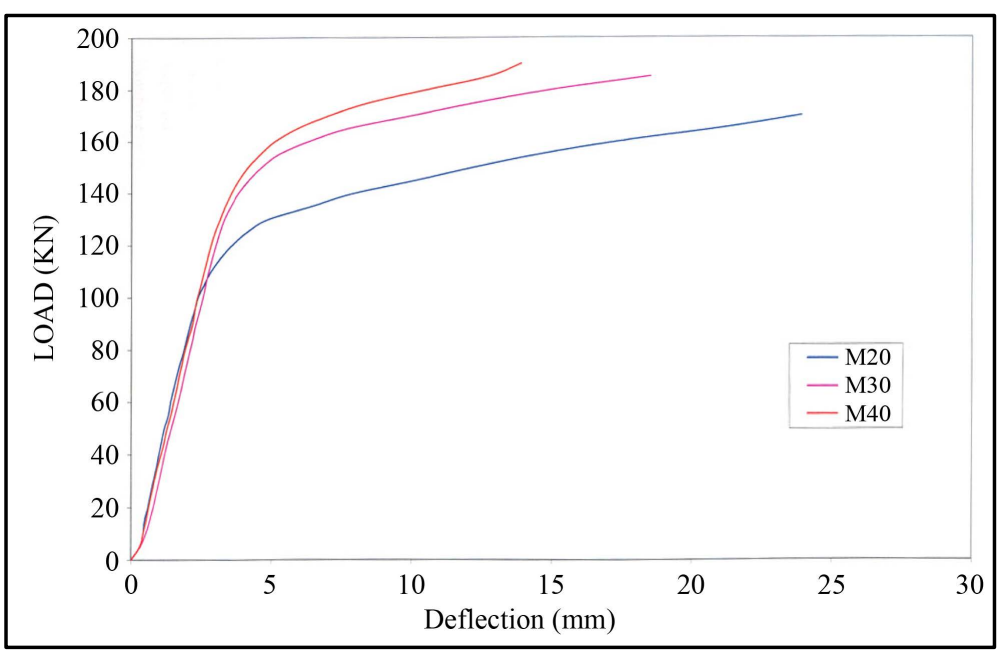

Figure 19. Comparison of load vs. deflection response M20, M30, and M40 specimens. 
Figure 19 shows the comparison of load vs deflection curves for M20, M30 and M40 grades of concrete filled CFSB members. It is clear from these curves that the CFSB members with higher grade will have higher moment carrying capacity.

\section{Conclusion}

A comparative study between conventional reinforced concrete members and concrete filled steel beam (CFSB) members has been made. This shows that high ductility as well as high moment carrying capacity could be expected from concrete filled steel box members. The fracture of the concrete filled members depends to a great extent on the fracture of the filled concrete and thus special care must be given to the casting of the concrete.

\section{Acknowledgements}

The publication fee for this research work is funded by the deanship of scientific research at Salman Bin Abdulaziz University for project \# 40/T/33.

\section{References}

[1] Uy, B. (2000) Strength of Concrete Filled Steel Box Columns Incorporating Local Buckling. Journal of Structural Engineering, 126, 341-352. http://dx.doi.org/10.1061/(ASCE)0733-9445(2000)126:3(341)

[2] Zhung, W.Z. and Shahrooz, B.M. (1999) Strength of Short and Long Concrete-Filled Tublar Columns. ACI Structural Journal, 96, 230-237.

[3] Uy, B. (2001) Local and Postlocal Buckling of Fabricated Steel and Composite cross Sections. Journal of Structural Engineering, 127, 666-677. http://dx.doi.org/10.1061/(ASCE)0733-9445(2001)127:6(666) 